\title{
Sleep Disturbances and Depressive and Anxiety Symptoms During Pregnancy: Associations With Delivery and Newborn Health
}

Hilla Maaria Peltonen ( $\sim$ himape@gmail.com )

Turku University Hospital https://orcid.org/0000-0003-3765-4393

Ella Juulia Paavonen

University of Helsinki and Helsinki University Hospital

Outi Saarenpää-Heikkilä

Tampere University and Tampere University Hospital https://orcid.org/0000-0002-5382-5888

Tero Vahlberg

University of Turku https://orcid.org/0000-0002-4935-3056

\section{Tiina Paunio}

Helsinki University Hospital and University of Helsinki

\section{Päivi Polo-Kantola}

University of Turku

\section{Research Article}

Keywords: Sleep disturbances, depression, anxiety, mother, delivery, newborn

Posted Date: November 9th, 2021

DOl: https://doi.org/10.21203/rs.3.rs-41849/v2

License: (9) (i) This work is licensed under a Creative Commons Attribution 4.0 International License.

Read Full License

Version of Record: A version of this preprint was published at Archives of Gynecology and Obstetrics on April 24th, 2022. See the published version at https://doi.org/10.1007/s00404-022-06560-x. 


\section{Abstract}

Background: Sleep disturbances and mood symptoms are common in late pregnancy and according to previous literature, they can affect delivery and newborn outcomes. This study evaluated the effect of sleep and mood symptoms on delivery and newborn health as there is insufficient and partly contradictory studies on the topic.

Methods: A cohort of 1414 mothers was enrolled in the third trimester to this prospective cross-sectional questionnaire study. Validated questionnaires were assessed for measurement of sleep disturbances, depressive and anxiety symptoms. The data on delivery and newborn outcomes was obtained from hospital medical records.

Results. Sleep disturbances were very common during pregnancy. Higher insomnia score $(\beta=-0.06, p=$ $0.047)$ and longer sleep need $(\beta=0.07, p=0.047)$ were related to delivery at a lower gestational age. In addition, higher insomnia score $(\beta=-28.30, p=0.010)$ and lower general sleep quality $(\beta=-62.15, p=$ 0.025 ) were associated with lower birth weight, but instead, longer sleep duration and longer sleep need with higher birth weight ( $\beta=28.06, p=0.019 ; \beta=27.61, p=0.028$, respectively). However, the findings regarding birth weight lost their significance when the birth weight was standardized with gestational weeks. Concerning Apgar scores and the umbilical artery $\mathrm{pH}$, no associations were found. Snoring was associated with a shorter duration of the 1st phase $(\beta=-78.71, p=0.015)$ and total duration of delivery ( $\beta$ $=-79.85, p=0.016)$. Mothers with higher insomnia, depressive or anxiety symptoms were more often treated with oxytocin (OR $1.5495 \% \mathrm{Cl} 1.00-2.38, p=0.049$, OR 1.76, 95\% Cl 1.02-3.04, $p=0.049$ and OR $1.91, \mathrm{Cl} 95 \% 1.28-2.84, p<0.001$, respectively) and those with higher depressive and anxiety symptoms delivered more often with elective caesarean section (OR 4.67, 95\% $\mathrm{Cl} 2.04-12.68, p<0.001$ and OR 2.22, $95 \% \mathrm{Cl} 1.03-4.79, p=0.042$ ).

Conclusions: Maternal sleep disturbances and mood symptoms during pregnancy are associated with delivery and newborn health. However, nearly all the outcomes fell within a normal range, implying that the actual risks are low.

\section{Introduction}

Pregnant women sleep poorly [1]. Sleep disturbances, especially insomnia symptoms, are common during pregnancy and often worsen towards the end of the pregnancy [2-5]. Insomnia symptoms, including difficulties to fall asleep (initiation insomnia), nightly awakenings and too early morning awakenings (maintenance insomnia) lead to decreased sleep time and poor overall sleep quality [6]. Occurrence of sleep disordered breathing (snoring, sleep apnea and partial upper airway obstruction) also increase during pregnancy $[5,7]$ probably due to increased weight, oedema, and nasal congestion [8].

Maternal sleep disturbances, especially poor sleep quality, short sleep duration and sleep disordered breathing may, according to previous studies, contribute to maternal morbidity and adverse delivery outcomes, such as preterm delivery $[9,10]$. In a study of 166 mothers by Okun and colleagues [11] poor 
sleep quality especially in early pregnancy (14-16 weeks), but also with a tendency in late pregnancy, was a predictor of preterm birth. Disrupted sleep leading to stress system activation, inflammatory response rise and changes in the hypothalamic-pituitary-adrenal axis (HPA) are suggested to be the potential underlying mechanisms [12].

Previous studies indicate that poor maternal sleep could also be associated with longer duration of delivery $[13,14]$ and may increase the risk of operative deliveries, especially of caesarean section [13-15]. In an Iranian study of 457 primiparas [13] short sleep duration in late pregnancy was associated with a longer duration of all the phases of delivery and women sleeping longer were more likely to deliver vaginally. Another Iranian study of 88 mothers found that women sleeping less $(6.45 \pm 2.07 \mathrm{~h}$ vs. $8.47 \pm$ $1.86 \mathrm{~h}$ ) per night had longer deliveries and $20 \%$ higher risk for caesarean delivery [16]. However, the previous literature is not unanimous, as some studies do not support the association between maternal sleep and delivery outcomes $[17,18]$. The lack of consensus may be due to varying study designs and differences in clinical practice or inadequate control of confounding factors [17]. Additionally, maternal sleep disturbances may raise a risk for the growing fetus; short sleep duration $[13,19]$ and habitual snoring $[8,20]$ have been shown to associate with adverse newborn outcomes, such as lower birth weight and lower Apgar scores.

Low sleep quality and short sleep duration during pregnancy and during the postpartum period are known risk factors for depressive and anxiety symptoms and vice versa [21-24]. Depressive and anxiety symptoms have also been linked with a higher occurrence of caesarean section in one study [25], but contradictory findings have also been presented [17, 26-28]. In a large systematic review article by Grigoriadis et al [26] including 29 original articles, anxiety during pregnancy was associated with adverse newborn outcomes like preterm delivery as well as lower birth weight and a smaller head circumference. However, maternal anxiety and newborn Apgar points were not associated. In a comprehensive review article written by the same author [29], maternal depression during pregnancy was associated with increased odds for preterm delivery and decreased breastfeeding initiation, but not with other delivery or newborn outcomes.

The aim of our study was to evaluate the association between maternal sleep disturbances and mood symptoms and delivery and newborn health. We concentrated on insomnia symptoms and sleep loss, as well as depressive and anxiety symptoms. We hypothesized that both sleep disturbances and mood symptoms would increase the risk of delivering earlier, longer delivery, operative delivery and relate to poorer health in the newborn.

\section{Methods}

\section{Subjects}

This prospective cross-sectional study was a part of a larger Finnish CHILD-SLEEP-birth cohort, which has been described in detail by Paavonen et al. [30]. Mothers were recruited by midwives or nurses in 
maternity clinics in the Pirkanmaa area during routine pregnancy-related check-ups in late pregnancy (around gestational week 32). All participants were given both oral and written information about the study. The mothers were eligible if they were willing to participate in the study, had sufficient language skills (Finnish) to complete the study questionnaires and if they gave their written consent to take part in the study. Altogether 1673 women participated in this study and 1598 questionnaires were returned.

Mothers who had an incomplete questionnaire, missing delivery or newborn data or who had completed the questionnaire before gestational week 24 or after the delivery were excluded $(n=116)$. The mothers filled in the questionnaire on average in the gestational week 35 (range 24-41). Since the delivery outcomes were of especial interest in our study, we also excluded twin pregnancies $(n=10)$ and pregnancies with a fetus in other than a cephalic presentation $(n=58)$. A final sample of 1414 women remained to form the study population. The mothers were recruited between April 2011 and December 2012, and the infants were born between April 2011 - February 2013. During that time period, approximately 7700 infants fulfilling the inclusion criteria were born in the target area, but due to the exclusion criteria, maternal refusals, language difficulties, and a failure on the prenatal nurses' part to present the survey to the mothers, the sample coverage was approximately $20 \%$ (Fig. 1).

\section{Questionnaires}

The sleep disturbances were evaluated with eight questions drawn from the Basic Nordic Sleep Questionnaire (BNSQ) [31] (general sleep quality, difficulties to fall asleep, nightly awakenings per week, number of awakenings per night, too early awakenings, self-reported snoring, sleep duration and sleep need). General sleep quality was rated on 5-point scale as 1 = 'good', 2 = 'quite good', 3 = 'intermediate (neither good nor poor)', $4=$ 'quite poor' or $5=$ 'poor', the frequency of nocturnal awakenings per night $1=$ 'none', 2 = 'once', 3 = 'twice', 4 = 'three to four times', 5 = 'at least five times' and the other questions with a 5-point scale as 1 = 'never or less than once a month', 2 = 'less than in one day a week', 3 = 'in one or two days a week', 4 = 'in three to five days a week' and 5 = 'daily or almost daily'.

To represent the severity of co-operative action of all the insomnia symptoms (general sleep quality, difficulties to fall asleep per week, nightly awakenings per week, number of awakenings per night, too early awakenings per week), a summary score was defined by dichotomizing the responses $\left(0={ }^{\prime} 1-2\right.$ times per week/night or less' vs $1=$ ' $3-5$ times or more per week/night'), and the scores were summed to form a insomnia score (range 0-5 points). Sum score of 4 points or more was considered deviant as then the mother would have had at least four different sleep disturbances occurring at least 3-5 times per week/night. Sleep duration (hours, h) was calculated as the average self-reported sleep time during weekdays and weekends and the sleep need as self-reported desired sleep time. In case the sleep times ranged over 2 hours, the reply was excluded. Sleep loss was defined by subtracting sleep need from sleep time. Sleep duration $<6$ hours and sleep loss $>2$ hours were defined deviant.

Depression was evaluated using the shortened 10-item version of the Center for Epidemiologic Studies Depression Scale (CES-D) [32] with ten questions in a scale from 0 to 3 in each question (range $0-30$ ). 
Scores were totaled to form a depression score and used in analyses both as a continuous and categorical (a total score $\geq 12$ points [95th percentile] was used as a cut-off point). A shortened StateTrait Anxiety Inventory (STAI) [33] was used to evaluate anxiety with six questions in a scale from 1 to 4 in each question (anxiety at all times and the person's vulnerability to anxiety). Scores were totaled to form an anxiety score (range 6-24) and used in analyses both as a continuous and categorical (a total score $\geq 12$ (95th percentile) was used as a cut-off point).

\section{Data of delivery and newborn health}

The data of the delivery and newborn health were collected from hospital medical records and hospital register data. Maternal delivery variables included gestational weeks at the time of delivery, duration of delivery (phase I [min], phase II [min], total duration [min]), the type of delivery (spontaneous vaginal/vacuum delivery/elective caesarean section/acute caesarean section), and the use of oxytocin for induction or augmentation during delivery (yes/no). The newborn variables were weight (grams), standardized birth weight, Apgar scores (at 1 minute and 5 minutes), and pH of the umbilical artery $(\mathrm{uApH})$ and umbilical vein $(\mathrm{uVpH})$ at birth.

\section{Statistical analyses}

Sleep variables, depressive and anxiety symptoms, delivery and newborn variables and basic characteristics were first submitted for descriptive analysis and were expressed as means and standard deviations (SD) and ranges or frequencies (numbers and percentages). Insomnia total score, sleep duration, sleep loss, CES-D total score (depression score) and STAI total score (anxiety score) were used both as continuous and dichotomous variables (cut off points: Insomnia score $\geq 4$, sleep duration $<6$ hours, sleep loss $>2$ hours, CES-D $\geq 12$, STAI $\geq 12$ ). Sleep need was considered as continuous and snoring as dichotomized (no = ' $1-2$ times per week/night or less' vs yes = '3-5 days or more a week'). Maternal age and BMI were considered as continuous. Delivery variables were considered as categorized, except for gestational weeks at birth, which were calculated as continuous. Newborn variables were considered as continuous, except for the Apgar scores, which were categorized as $\leq 7$ or $>7$ (both at 1 minute and 5 minutes).

Finally, we conducted a series of regression models to control for potentially confounding background factors (age, parity, BMI, general health, smoking and education). Linear regression models were used to study factors related to gestational age, birth weight and standardized birth weight, duration of delivery (phases I and II and total duration) and birth variables (Apgar scores at 1 and 5 minutes and uApH).

Logistic regression was used to study the odds of oxytocin use and elective caesarean section. The cases with caesarean section were excluded from the models where birth variables or duration of delivery were studied (the $n$ in the models varied between 1258-1268).

In the modelling, each explanatory factor was studied separately to control for the confounding factors in the statistical models. $P$-values of $<0.05$ were considered as statistically significant and are bolded in the tables. Statistical computations were performed using SPSS Statistics 26 data program. 


\section{Results}

\section{Basic characteristics}

Maternal characteristics are shown in Table 1. Sociodemographic factors included age (years), parity (nulliparous/multiparous) and education (low [no education or vocational training]/intermediate/high [university]). Health behavior factors included body mass index at the time of the survey $\left(\mathrm{BMI}, \mathrm{kg} / \mathrm{m}^{2}\right.$ ) and smoking (yes/no). Questions about the participant's state of health comprised of the existence of a long-term disease/disability (yes/no; if yes, specify).

Table 1

Basic characteristics

\begin{tabular}{|llll|}
\hline & $n$ & Mean (SD) or \% & Range \\
\hline Age (years) & 1411 & $30.6(4.6)$ & $17-48$ \\
\hline BMI $\left(\mathrm{kg} / \mathrm{m}^{2}\right)$ & 1376 & $28.4(4.4)$ & $19.2-47.6$ \\
\hline Vocational education & 1382 & & \\
\hline None or some vocational training & 99 & $7.2 \%$ & \\
\hline Vocational degree or polytechnic & 797 & $57.7 \%$ & \\
\hline University & 486 & $35.2 \%$ & \\
\hline Parity & 1319 & & \\
\hline Nulliparous & 612 & $46.4 \%$ & \\
\hline Multiparous & 707 & $53.6 \%$ & \\
\hline Smoking during pregnancy & 1409 & & \\
\hline Yes & 84 & $6.0 \%$ & \\
\hline Long term disability or illness & 1414 & \\
\hline Yes & 305 & $21.6 \%$ \\
\hline BMI body mass index & & \\
\hline
\end{tabular}

\section{Maternal sleep quality and mood symptoms}

Sleep disturbances, sleep durations and depressive and anxiety symptoms are described in Tables 2-3. The most common sleep disturbance was nocturnal awakenings, with $98.6 \%$ of the mothers experiencing this weekly and $83.4 \%$ daily. 
Table 2

Maternal sleep duration, insomnia and mood symptoms

\begin{tabular}{|llll|}
\hline & $n$ & Mean (SD) or \% & Range \\
\hline Sleep duration (min) & 1408 & $484(63)$ & $180-720$ \\
\hline Sleep duration < 6 hours & 59 & $4.2 \%$ & \\
Sleep need (min) & 1403 & $529(60)$ & $300-1140$ \\
Sleep loss (min) & 1398 & $45(63)$ & $-240-+600$ \\
Sleep loss > 2 hours & 100 & $7.2 \%$ & $0-5.0$ \\
\hline Insomnia score & 1406 & $1.8(1.1)$ & $0-23.0$ \\
\hline Depression score (CES-D) & 1410 & $5.2(3.5)$ & $6-21.0$ \\
\hline Anxiety score (STAl) & 1413 & $9.0(2.4)$ & \\
\hline CES-D Center for Epidemiologic Studies Depression Scale, STA/State-Trait Anxiety inventory, \\
\hline
\end{tabular}


Table 3

Maternal sleep quality and specific sleep disturbances

\begin{tabular}{|c|c|c|c|c|c|c|}
\hline & $\begin{array}{l}\text { total } \\
n\end{array}$ & $n(\%)$ & $n(\%)$ & $n(\%)$ & $n(\%)$ & $n(\%)$ \\
\hline & & $\begin{array}{l}\text { Never or less } \\
\text { than }\end{array}$ & $\begin{array}{l}\text { Less than } \\
\text { one }\end{array}$ & $\begin{array}{l}\text { On 1-2 } \\
\text { days }\end{array}$ & $\begin{array}{l}\text { On 3-5 } \\
\text { days }\end{array}$ & $\begin{array}{l}\text { Daily or } \\
\text { almost daily }\end{array}$ \\
\hline & & $\begin{array}{l}\text { once a } \\
\text { month }\end{array}$ & $\begin{array}{l}\text { day a } \\
\text { week }\end{array}$ & a week & a week & \\
\hline & & or night & or night & or night & or night & \\
\hline $\begin{array}{l}\text { Difficulties to fall } \\
\text { asleep }\end{array}$ & 1414 & $495(35.0 \%)$ & $\begin{array}{l}428(30.3 \\
\%)\end{array}$ & $\begin{array}{l}295(20.9 \\
\%)\end{array}$ & $\begin{array}{l}133 \\
(9.4 \%)\end{array}$ & $63(4.5 \%)$ \\
\hline $\begin{array}{l}\text { Awakenings per } \\
\text { week }\end{array}$ & 1413 & $4(0.4 \%)$ & $14(1.0 \%)$ & $57(4.0 \%)$ & $\begin{array}{l}160 \\
(11.3 \\
\%)\end{array}$ & $\begin{array}{l}1178(83.4 \\
\%)\end{array}$ \\
\hline $\begin{array}{l}\text { Awakenings per } \\
\text { night }\end{array}$ & 1408 & $23(1.6 \%)$ & $\begin{array}{l}394(28.0 \\
\%)\end{array}$ & $\begin{array}{l}490(34.8 \\
\%)\end{array}$ & $\begin{array}{l}436 \\
(31.0 \\
\%)\end{array}$ & $65(4.6 \%)$ \\
\hline $\begin{array}{l}\text { Too early } \\
\text { awakenings }\end{array}$ & 1413 & 507 (35.9 \%) & $\begin{array}{l}454(32.1 \\
\%)\end{array}$ & $\begin{array}{l}305(21.6 \\
\%)\end{array}$ & $\begin{array}{l}114 \\
(8.1 \%)\end{array}$ & $33(2.3 \%)$ \\
\hline \multirow[t]{2}{*}{ Snoring } & 1360 & $831(61.1 \%)$ & $\begin{array}{l}196(14.4 \\
\%)\end{array}$ & $\begin{array}{l}142(10.4 \\
\%)\end{array}$ & $\begin{array}{l}69(5.1 \\
\%)\end{array}$ & $122(9.0 \%)$ \\
\hline & & Well & Quite well & Intermediate & $\begin{array}{l}\text { Quite } \\
\text { poor }\end{array}$ & Poor \\
\hline $\begin{array}{l}\text { General sleep } \\
\text { quality }\end{array}$ & 1414 & 194 (13.7 \%) & $\begin{array}{l}550(38.9 \\
\%)\end{array}$ & $\begin{array}{l}284(20.1 \\
\%)\end{array}$ & $\begin{array}{l}330 \\
(23.3 \\
\%)\end{array}$ & $56(4.0 \%)$ \\
\hline
\end{tabular}

\section{Delivery and newborn outcomes}

Of all mothers, $98.2 \%$ had a full term pregnancy ( $\geq 37$ gestational weeks, range 33-42) and $82.3 \%$ delivered vaginally. Of the operative deliveries, the caesarean section rate was low $10.0 \%$ and the vacuum extraction rate $7.6 \%$. Oxytocin (induction or augmentation) was used in over half of deliveries (Table 4). 
Table 4

Delivery and newborn outcomes

\begin{tabular}{|c|c|c|c|}
\hline & $n$ & $\%$ or Mean (SD) & Range \\
\hline Gestational age at delivery (weeks) & 1414 & $40.1(1.2)$ & $33.0-42.7$ \\
\hline Delivery < 37 gestational weeks (\%) & 25 & $1.8 \%$ & \\
\hline Delivery type & 1410 & & \\
\hline Spontaneous vaginal & 1162 & $82.4 \%$ & \\
\hline Vacuum & 106 & $7.5 \%$ & \\
\hline Elective caesarean & 41 & $2.9 \%$ & \\
\hline Acute caesarean & 101 & $7.2 \%$ & \\
\hline \multicolumn{4}{|l|}{ Duration of delivery } \\
\hline Duration phase I (min) & 1407 & $480(350)$ & $10-2315$ \\
\hline Duration phase II (min) & 1268 & $21(19)$ & $1-114$ \\
\hline Total duration (min) & 1407 & $511(362)$ & $10-2357$ \\
\hline Oxytocin use & 1411 & & \\
\hline Yes & 811 & $57.5 \%$ & \\
\hline Birth weight (gram) & 1414 & $3597(449)$ & $1950-5780$ \\
\hline Birth weight Z-score & 1414 & $-0.1(0.9)$ & $-2.8-+6.4$ \\
\hline Birth length $(\mathrm{cm})$ & 1414 & $50.5(1.9)$ & $42.0-58.0$ \\
\hline Birth length Z-score & 1414 & $0.0(1.0)$ & $-3.9-+4.9$ \\
\hline Head circumference $(\mathrm{cm})$ & 1412 & $35.0(1.4)$ & $30.5-40.0$ \\
\hline Head circumference Z-score & 1412 & $0.0(1.0)$ & $-3.0-+3.6$ \\
\hline \multicolumn{4}{|l|}{ Apgar scores } \\
\hline 1 minutes & 1403 & 8.5 & $1-10$ \\
\hline 5 minutes & 1401 & 8.9 & $3-10$ \\
\hline \multicolumn{4}{|l|}{ Newborn pH } \\
\hline Artery & 1398 & 7.3 & $6.8-7.6$ \\
\hline Vein & 203 & 7.3 & 7.0-7.5 \\
\hline
\end{tabular}


Of all the newborns, $1.2 \%(n=19)$ had a standardized birth weight under -2 SD and $2 \%(n=28)$ over +2 SD. Umbilical artery $\mathrm{pH}(\mathrm{uApH})$ was normal in most cases of the newborns: $3.2 \%(n=45)$ had a uApH < 7.10 and only $0.1 \%(n=2) \mathrm{uApH}<7.00$. The vein $\mathrm{pH}$ was available only in 203 newborns and it was thus not included in the analysis. The 1-minute Apgar scores were $<7$ in $3.1 \%(n=44)$ and the 5 -minutes Apgar scores were $<7$ in $0.1 \%(n=4)$. The newborn data is shown in Table 4 .

\section{Associations between maternal sleep quality and mood symptoms and delivery outcomes}

Mothers with a higher insomnia score delivered at a lower gestational age (Table 5); a one point increase in the insomnia score shortened the duration of pregnancy, on average by half ( 0.5$)$ day ( 0.06 week). In addition, longer sleep need was associated with slightly ( 0.5 days) longer duration of pregnancy (Table 5). The results remained after controlling for the other sleep variables and mood symptoms. However, the mean gestational week at delivery fell within the normal range in the entire sample. Sleep loss was associated with longer duration of phase 1 and longer total duration of the delivery (Table 6). Instead, snoring was associated with a shorter duration of phase I and a shorter total duration of the delivery. 
Table 5

Associations between maternal sleep quality, mood symptoms and gestational age and birth weight

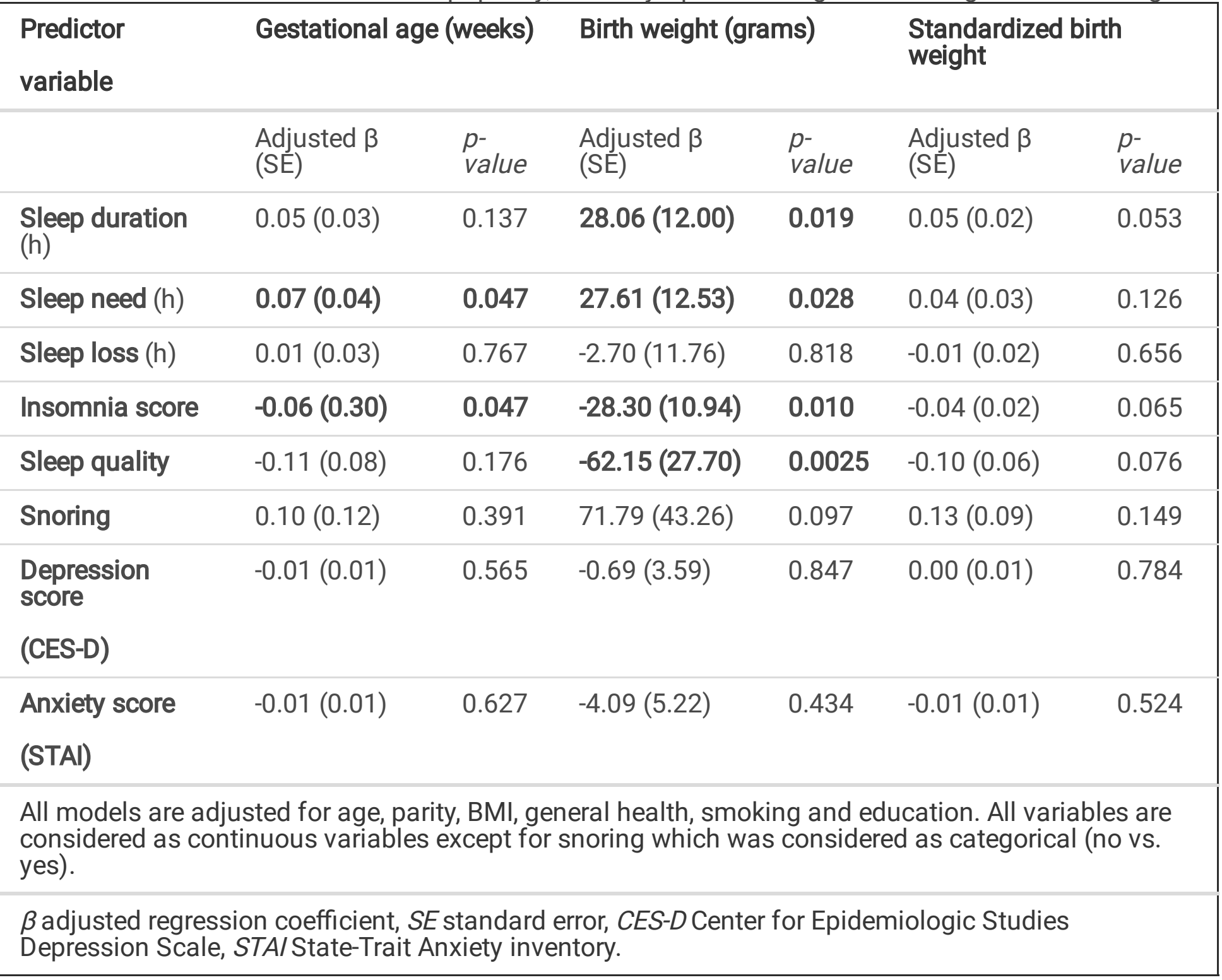


Table 6

Associations between maternal sleep quality and mood symptoms and duration of delivery in women with vaginal (spontaneous or assisted) delivery

\begin{tabular}{|c|c|c|c|c|c|c|}
\hline \multirow[t]{2}{*}{ Explanatory variable } & \multicolumn{2}{|l|}{ I phase ${ }^{2}$} & \multicolumn{2}{|l|}{ II phase ${ }^{2}$} & \multicolumn{2}{|l|}{ Total duration ${ }^{2}$} \\
\hline & $\begin{array}{l}\text { Adjusted }{ }^{1} \beta \\
\text { (SE) }\end{array}$ & $\begin{array}{l}p- \\
\text { value }\end{array}$ & $\begin{array}{l}\text { Adjusted }{ }^{1} \beta \\
\text { (SE) }\end{array}$ & $\begin{array}{l}p- \\
\text { value }\end{array}$ & $\begin{array}{l}\text { Adjusted }{ }^{1} \beta \\
\text { (SE) }\end{array}$ & $\begin{array}{l}p- \\
\text { value }\end{array}$ \\
\hline Sleep duration (h) & $-0.011(0.01)$ & 0.124 & $0.011(0.012)$ & 0.360 & $-0.010(0.007)$ & 0.151 \\
\hline Sleep need (h) & $0.010(0.01)$ & 0.213 & $0.004(0.012)$ & 0.749 & $0.010(0.007)$ & 0.199 \\
\hline Sleep loss (h) & $0.019(0.01)$ & 0.001 & $\begin{array}{l}-0.007 \\
(0.001)\end{array}$ & 0.525 & $0.017(0.007)$ & 0.012 \\
\hline Insomnia score & $-0.001(0.07)$ & 0.905 & $0.003(0.01)$ & 0.759 & $0.00(0.006)$ & 0.959 \\
\hline Snoring & $-0.07(0.03)$ & 0.010 & $\begin{array}{l}-0.057 \\
(0,043)\end{array}$ & 0.181 & $-0.063(0.026)$ & 0.015 \\
\hline $\begin{array}{l}\text { Depression score } \\
\text { (CES-D) }\end{array}$ & $0.001(0.002)$ & 0.815 & $0.001(0.003)$ & 0.865 & $0.00(0.002)$ & 0.823 \\
\hline Anxiety score (STAI) & $\begin{array}{l}-0.001 \\
(0.003)\end{array}$ & 0.778 & $0.004(0.005)$ & 0.433 & $-0.001(0.003)$ & 0.787 \\
\hline \multicolumn{7}{|c|}{$\begin{array}{l}{ }^{1} \text { All models are adjusted for age, parity, BMI, general health, smoking and education. Models are } \\
\text { performed only in women with vaginal delivery (spontaneous vacuum assisted, } n=1268 \text { ). }\end{array}$} \\
\hline \multicolumn{7}{|c|}{$\begin{array}{l}{ }^{2} \text { All outcome variables were log transformed before analyses. All variables are considered as } \\
\text { continuous variables except for snoring which was considered as categorical (no vs. yes). }\end{array}$} \\
\hline
\end{tabular}

When considered as categorical, a high level of insomnia score, a high level of depression score and a high-level anxiety score were related to higher odds for being treated with oxytocin during delivery and higher depressive and anxiety scores with higher odds for elective (but not with acute) caesarean section (Table 7). No other associations with delivery outcomes emerged.

\section{Associations between maternal sleep quality and mood symptoms and newborn outcomes}

Mothers with higher insomnia scores and lower general sleep quality delivered infants with lower weight (Table 5). Furthermore, those with longer sleep duration and longer sleep need delivered infants with higher weight. However, when the gestational week at delivery was considered using standardized birth weight as outcome, all these findings lost their statistical significance (Table 5). Concerning Apgar scores and the $\mathrm{uApH}$, no associations between the sleep variables or mood symptoms were found (data not shown). 
All the above-mentioned results remained when the other sleep variables and mood symptoms were considered in the statistical modelling (data not shown).

Table 7. Odds rations for oxytocin use in women with vaginal delivery $(n=1268)$

and risk for elective cesarean section in all women $(n=1410)$

Explanatory variable

Oxytocin use

Elective Caesarean Section

Adjusted OR $(95 \%$

$\mathrm{Cl})$

p-

Adjusted OR (95\% p-

value

Cl)

value

Sleep duration ( $<6$ hours)

$1.27(0.65-2.49)$

0.481

$1.66(0.47-5.81)$

0.430

Sleep loss ( $>2$ hours)

$0.86(0.53-1.41)$

0.553

$1.46(0.49-4.33)$

0.497

Insomnia score $<$ vs. $\geq 4$

1.54 (1.00-2.38)

0.049

$0.84(0.29-2.44)$

0.743

Snoring (no vs. yes)

1.01 (0.64-1.60)

0.969

$2.17(0.03-4.40)$

0.074

Depression score (CES-D) (< vs.

$\geq 12$ )

$1.76(1.02-3.04)$

0.044

$4.67(2.04-10.68)$

$<0.001$

Anxiety score (STAl) (< vs. $\geq 12$ )

$1.91(1.28-2.84)$

0.001

$2.22(1.03-4.79)$

0.042

${ }^{1}$ All models are adjusted for age, parity, BMI, general health, smoking and education. All explanatory variables are considered as categorical variables.

OR adjusted odds ratio, $C /$ confidence interval, CES-D Center for Epidemiologic Studies Depression Scale, STA/State-Trait Anxiety inventory.

\section{Discussion}

In our sample, comprising of late gestational week pregnancies, both insomnia and sleepiness symptoms were very common. As described earlier in this article, we found some specific correlations between sleep disturbances and delivery and newborn outcomes. However, the absolute risks related to insomnia and mood symptoms were small and thus their clinical significance remains unclear.

As stated earlier in this article; maternal poor sleep during pregnancy is a risk factor for preterm delivery $[9,10]$. We could not confirm this finding of prematurity, but still in our study insomnia symptoms were associated with delivery in earlier gestational weeks, albeit the effect was low. We also found that longer sleep duration and higher sleep need were associated with slightly longer duration of pregnancy. This finding supports the thought of sufficient sleep leading to a better pregnancy outcome. Of note was, however, that sleep loss, calculated by subtracting sleep need from sleep duration, was not associated with any delivery or newborn variables.

Our sample was recruited relatively late in the third trimester and thus the actual insomnia symptoms may have been short time, which could explain our weaker findings. In addition, the women delivering 
very preterm were presumably less likely to participate in the study as the recruitment of the participants started around 30th week of pregnancy. Thus, more studies are warranted, particularly using follow-up samples starting already from early pregnancy.

Prior research concerning maternal sleep disturbances and duration and type of delivery is limited and partly controversial. Insomnia symptoms and short sleep duration, especially during the last trimester, have been suggested to predispose to a longer duration of delivery $[13,16]$. We found partly similar results; sleep loss was associated with longer first phase and total time of the delivery. On the other hand, in our study, neither sleep disturbances, sleep quality or total sleep duration were associated with the duration of delivery. This is consistent with an American study with 99 mothers [18] which found no effect of sleep quality or sleep duration on the duration of delivery phases. One explanation for inconsistencies in results could be the varying clinical practices between the countries and the differences in the ways of notating the delivery durations.

Concerning the mode of the delivery, in the group of 131 American mothers [14], sleeping less than six hours per night one week before delivery was a risk factor for unplanned caesarean section. Moreover, the two earlier described Iranian studies $[13,16]$ found that both low sleep quality and short sleep duration in the third trimester were risk factors for caesarean section in general. In a large Swedish study [34], the researches screened retrospectively the electronic perinatal records of 6467 primiparas for free-text words that indicated stress, sleep disturbances and worry, and found that the existence of these words in the charts predicted an increased risk for an emergency caesarean section. In addition, in a Taiwanese study of 120 mothers [35], poor sleepers in the third-trimester were more likely to have a vacuum-assisted delivery. We could not confirm the associations between sleep disturbances and the mode of delivery. We found no correlation between maternal sleep and caesarean section, neither elective nor acute, which is in line with the results of the earlier mentioned American study [18] and also with a Canadian study of 624 women [17]. Of note is, that assessment of sleep disturbances in previous studies has varied widely and structured sleep questionnaires, as used in our study, have been utilized seldom. Furthermore, the frequencies of instrumental deliveries, and especially the rates of caesarean section ranges considerably between the studies (and countries) from our $10 \%$ to even $55 \%$ [15-17].

According to our results, snoring was associated with delivery duration, however, in contrast to our expectations, it was associated with a shorter delivery duration. The reason for this finding is unclear and its meaning remains uncertain. Earlier, in a large American study of 1673 mothers, snoring during pregnancy was associated not only with a lower birth weight but also with a higher risk of an elective and emergency caesarean section [8]. In another study [36], however, no association between snoring and delivery was found. Nevertheless, in our study, snoring did not relate to other delivery or newborn outcomes so this finding could also be a random association. Comparing previous studies is challenging, as the methodology varies between the studies.

Depressive symptoms prior to delivery have been reported to increase the risk of emergency caesarean section [25]. We found only that severe mood symptoms, both depressive and anxiety symptoms, were 
associated with elective caesarean section: mothers with higher depressive score had an almost five times and mothers with higher anxiety scores an over two times higher incidence. No association with emergency caesarean emerged. Our finding of the risk for elective caesarean is probably explained by fear of childbirth. Mood symptoms, anxiety and depression, co-exist often with the fear of child birth [37], and willingness to undergo a caesarean section among these mothers is common and today fear of giving birth is the leading cause for elective cesarean in Finland. The importance of our finding was notable, especially since the caesarean section rate in our study was low as the sample was recruited at the third trimester and breech and twin pregnancies were excluded. The overall elective caesarean section rate in Finland was 7,0\% in 2019 (thl.fi).

High insomnia score, high depressive score and high anxiety score correlated with the use of oxytocin during delivery. These findings were novel ones. Oxytocin causes the contractions of the uterus during delivery and stimulates lactation [38]. It also plays an important role in increasing maternal-fetal trust and bonding and modulates fear, stress and anxiety [39]. Anxiety which occurs in the third trimester and during delivery has been shown to have negative effects on the duration of all the phases of delivery [40]. In addition, in a recent large retrospective study women exposed to additional oxytocin during delivery were at a higher risk for the development of postpartum depressive and anxiety disorders [41]. Mood symptoms often co-exist with insomnia, so the finding of all these symptoms leading to the need of oxytocin is rational. It is possible that pregnant women suffering from insomnia or mood symptoms have lower levels of oxytocin during delivery or they have a decreased binding ability of oxytocin to the uterine oxytocin receptors and therefore these women need additional oxytocin stimulus. Unfortunately, in our cohort we could not reliably find out whether the oxytocin used during deliveries was for induction or for augmentation. In addition, the use of oxytocin during delivery is also dependent on the physician and mid-wife policy and can vary widely. As oxytocin is important in maternal-fetal bonding and presumably is lower in mothers with anxiety, more research is needed to better understand the possible associations.

There are only few studies addressing the relationship between maternal sleep and mood symptoms and newborn outcomes, but most of these studies concentrate on maternal sleep duration. Sleep loss has shown to negatively relate to fetal growth and lead to a lower birth weight [19]. We found that higher insomnia scores and lower general sleep quality were associated with lower birth weight and longer sleep duration and longer sleep need with slightly higher birth weight. Nevertheless, when the birth weight was standardized with gestational age at delivery, all these associations disappeared. This emphasizes the importance to control for gestational length when studying birth weight. It has also been hypothesized that as a consequence of the suboptimal prenatal environment, the fetus has less resources at birth, resulting in lower Apgar scores [12]. Again, according to the Iranian study with 457 participants, mothers sleeping less than eight hours per day in the third trimester have shown to deliver newborns with lower Apgar scores compared to mothers sleeping longer [13]. Nonetheless, in that study, the clinical relevance of the finding remained unclear, since the Apgar scores of the newborn of short sleeping mothers fell also within the normal range. In our study, no clinically relevant correlations emerged. This was true also in a Chinese study with 248 women and in a Canadian study with 650 mothers, where no correlations 
between maternal sleep variables and newborn health state at delivery were found [17, 35]. However, of note is, that our study did not consider the effect in the case of very preterm newborns.

Our study comprised of a large sample of pregnant Finnish women recruited during the third trimester and delivery and newborn data drawn from registers. Based on validation studies, the accountability and coverage of the Finnish health care register data are high and reliable [42]. We used questionnaires, which have been shown to be valid and reliable [31] and have been used in similar studies earlier [43]. However, there were limitations to the study. In our cohort, the caesarean and vacuum assisted delivery rates were significantly lower than in the general population in Finland and therefore there might be a selection bias in the results. Concerning the caesarean, the main reason for the low rate was the exclusion of breech presentation, twin pregnancies, and very preterm deliveries. The study assessed maternal sleep over the past months before delivery and can therefore reliably present only the effect of sleep in late pregnancy. The study was based on subjective questionnaires and no objective sleep data was collected. It is known that objective measurements of sleep can differ considerably from subjective self-reported sleep [44]. Nevertheless, the report errors were randomly distributed and thus equivalent for all the participants. In addition, our cohort comprised of women delivering mainly full term and thus our study did not consider the effects in the case of very preterm newborns, so the results cannot be interpreted in preterm cases.

\section{Conclusions}

In our study we found statistically significant associations between both sleep quality and mood symptoms and delivery and newborn outcomes, but the absolute risks were small. Although this finding can be considered favorable, sleep disturbances and mood symptoms are still a major health issue during pregnancy. It is important to notice that maternal sleeping problems and mood symptoms are clinically highly relevant regarding for example maternal subjective wellbeing and risk for post-partum depression [43] and therefore should also be considered as possible risk factors for undesirable delivery outcomes and poorer newborn health. However, it might ease the burden of stress related to course of pregnancy to know that risk related to insomnia and mood symptoms on delivery and new-born appear to be small. Finally, it is of note that our data represented only symptoms in late pregnancy and thus our results cannot be extrapolated in the situation of mothers with long term insomnia and mood symptoms. Therefore, future studies recruiting mothers in early pregnancy or even before pregnancy are needed.

\section{Abbreviations}

BNSQ: Basic Nordic Sleep Questionnaire; BMI: body mass index; CES-D: Center for Epidemiologic Studies Depression Scale; STAI: State-Trait Anxiety Inventory.

\section{Declarations}

\section{Ethical approval:}


The Study protocol was approved by Pirkanmaa Hospital District Ethical Committee (9.3.2011, ethical research permission code R11032). In addition, permission for recruitment procedure was also requested from the leading physicians of the 20 target health centers in Pirkanmaa area. All the participants gave a written consent.

\section{Consent for publication}

Not applicable

\section{Availability of data and materials}

The data that support the findings of this study are available from the Finnish Institute for Health and Welfare but restrictions apply to the availability of these data, which were used under license for the current study, and so are not publicly available. Data are however available from the authors upon reasonable request and with permission of The Finnish Institute for Health and Welfare.

\section{Competing interests:}

All authors have no conflicts of interest pertaining to this manuscript. Additionally, all authors declare that they have contributed to this manuscript.

\section{Funding:}

The study was financially supported by Turku University Hospital (EVO grant, P.P-K), Academy of Finland (\#308588 to E.J.P, \#277557 to O.S-H), Pediatric Research Foundation (E.J.P) and The Competitive Research Financing of the Expert Responsibility area of Tampere University Hospital (O.S-H).

\section{Authors' Contributions:}

Hilla Peltonen is the principal investigator and writer of the paper. Juulia E. Paavonen is a co-investigator and co-writer and major contributor in the statistical analyses. Tiina Paunio and Outi Saarenpää-Heikkilä are co-investigators in the larger Child-Sleep Study and Tero Vahlberg is a statistician consulted during the writing. Päivi Polo-Kantola is the leader of the study, co-investigator, and co-writer. All authors read and approved the final manuscript.

\section{References}

1. Lee KA, Zaffke ME, McEnany G (2000) Parity and sleep patterns during and after pregnancy. Obstet Gynecol 95:14-18. https://doi.org/10.1016/S0029-7844(99)00486-X

2. Hertz G, Feinsilver SH, Albertario CL et al (1992) Sleep in Normal Late Pregnancy. Sleep 15:246-251

3. Mindell JA, Jacobson BJ (2000) Sleep disturbances during pregnancy. J Obstet Gynecol Neonatal Nurs 29:590-597. https://doi.org/10.1111/j.1552-6909.2000.tb02072.x 
4. Facco FL, Kramer J, Ho KH et al (2010) Sleep Disturbances in Pregnancy. Obstet Gynecol 115:77-83. https://doi.org/10.1097/AOG.0b013e3181c4f8ec

5. Hedman C, Pohjasvaara T, Tolonen U et al (2002) Effects of pregnancy on mothers' sleep. Sleep Med 3:37-42. https://doi.org/10.1016/S1389-9457(01)00130-7

6. Morin CM, LeBlanc M, Daley M et al (2006) Epidemiology of insomnia: Prevalence, self-help treatments, consultations, and determinants of help-seeking behaviors. Sleep Med 7:123-130. https://doi.org/10.1016/j.sleep.2005.08.008

7. Leung PL, Hui DSC, Leung TN et al (2005) Sleep disturbances in Chinese pregnant women. BJOG An Int J Obstet Gynaecol 112:1568-1571. https://doi.org/10.1111/j.1471-0528.2005.00737.x

8. O’Brien LM, Bullough AS, Owusu JT et al (2013) Snoring during pregnancy and delivery outcomes: a cohort study. Sleep 36:1625-1632. https://doi.org/10.5665/sleep.3112

9. Okun ML, Roberts JM, Marsland AL, Hall M (2009) How disturbed sleep may be a risk factor for adverse pregnancy outcomes. Obstet Gynecol Surv 64:273-280.

https://doi.org/10.1097/OGX.0b013e318195160e

10. Micheli K, Komninos I, Bagkeris E et al (2011) Sleep Patterns in Late Pregnancy and Risk of Preterm Birth and Fetal Growth Restriction. Epidemiology 22:738-744.

https://doi.org/10.1097/EDE.0b013e31822546fd

11. Okun ML, Schetter CD, Glynn LM (2011) Poor Sleep Quality is Associated with Preterm Birth. Sleep 34:1493-1498. https://doi.org/10.5665/sleep.1384

12. Palagini L, Gemignani A, Banti $S$ et al (2014) Chronic sleep loss during pregnancy as a determinant of stress: impact on pregnancy outcome. Sleep Med 15:853-859.

https://doi.org/10.1016/j.sleep.2014.02.013

13. Zafarghandi N, Hadavand S, Davati A et al (2012) The effects of sleep quality and duration in late pregnancy on labor and fetal outcome. J Matern Fetal Neonatal Med 25:535-537. https://doi.org/10.3109/14767058.2011.600370

14. Lee KA, Gay CL (2004) Sleep in late pregnancy predicts length of labor and type of delivery. Am J Obstet Gynecol 191:2041-2046. https://doi.org/10.1016/j.ajog.2004.05.086

15. Li R, Zhang J, Zhou R et al (2017) Sleep disturbances during pregnancy are associated with cesarean delivery and preterm birth. J Matern Neonatal Med 30:733-738.

https://doi.org/10.1080/14767058.2016.1183637

16. Naghi I, Keypour F, Ahari SB et al (2011) Sleep disturbance in late pregnancy and type and duration of labour. J Obstet Gynaecol 31:489-491. https://doi.org/10.3109/01443615.2011.579196

17. Hall WA, Stoll K, Hutton EK, Brown H (2012) A prospective study of effects of psychological factors and sleep on obstetric interventions, mode of birth, and neonatal outcomes among low-risk British Columbian women. BMC Pregnancy Childbirth 12:78. https://doi.org/10.1186/1471-2393-12-78

18. Evans ML, Dick MJ, Cark AS Sleep during the Week before Labor: Relationships to Labor Outcomes 
19. Abeysena C, Jayawardana P, Seneviratne DEA R (2009) Maternal sleep deprivation is a risk factor for small for gestational age: a cohort study. Aust N Z J Obstet Gynaecol 49:382-387. https://doi.org/10.1111/j.1479-828X.2009.01010.x

20. Pamidi S, Pinto LM, Marc I et al (2014) Maternal sleep-disordered breathing and adverse pregnancy outcomes: a systematic review and metaanalysis. Am J Obstet Gynecol 210:52.e1-52.e14. https://doi.org/10.1016/J.AJOG.2013.07.033

21. Tomfohr LM, Buliga E, Letourneau NL et al (2015) Trajectories of sleep quality and associations with mood during the perinatal period. Sleep 38:1237-1245. https://doi.org/10.5665/sleep.4900

22. Dørheim SK, Bondevik GT, Eberhard-Gran M, Bjorvatn B (2009) Sleep and depression in postpartum women: a population-based study. Sleep 32:847-855

23. Bei B, Coo S, Trinder J (2015) Sleep and Mood During Pregnancy and the Postpartum Period. Sleep Med Clin 10:25-33. https://doi.org/10.1016/J.JSMC.2014.11.011

24. Polo-Kantola P, Aukia L, Karlsson $\mathrm{H}$ et al (2017) Sleep quality during pregnancy: associations with depressive and anxiety symptoms. Acta Obstet Gynecol Scand 96:198-206. https://doi.org/10.1111/aogs.13056

25. Bayrampour H, Salmon C, Vinturache A, Tough S (2015) Effect of depressive and anxiety symptoms during pregnancy on risk of obstetric interventions. J Obstet Gynaecol Res 41:1040-1048. https://doi.org/10.1111/jog.12683

26. Grigoriadis S, Graves L, Peer M et al (2018) Maternal Anxiety During Pregnancy and the Association With Adverse Perinatal Outcomes. J Clin Psychiatry 79:0-0. https://doi.org/10.4088/JCP.17r12011

27. Reck C, Zimmer K, Dubber S et al (2013) The influence of general anxiety and childbirth-specific anxiety on birth outcome. Arch Womens Ment Health 16:363-369. https://doi.org/10.1007/s00737013-0344-0

28. Tsai S-Y, Lin J-W, Kuo L-T et al (2013) Nighttime sleep, daytime napping, and labor outcomes in healthy pregnant women in Taiwan. Res Nurs Health 36:612-622. https://doi.org/10.1002/nur.21568

29. Grigoriadis S, VonderPorten EH, Mamisashvili L et al (2013) The impact of maternal depression during pregnancy on perinatal outcomes: A systematic review and meta-analysis. J Clin Psychiatry 74:. https://doi.org/10.4088/JCP.12r07968

30. Juulia Paavonen E, Saarenpää-Heikkilä O, Pölkki P et al (2017) Maternal and paternal sleep during pregnancy in the Child-sleep birth cohort. Sleep Med 29:. https://doi.org/10.1016/j.sleep.2016.09.011

31. Partinen M, Gislason T (1995) Basic Nordic Sleep Questionnaire (BNSQ): a quantitated measure of subjective sleep complaints. J Sleep Res 4:150-155. https://doi.org/10.1111/j.13652869.1995.tb00205.x

32. Irwin M, Artin KH, Oxman MN (1999) Screening for Depression in the Older Adult. Arch Intern Med 159:1701. https://doi.org/10.1001/archinte.159.15.1701

33. Bieling PJ, Antony MM, Swinson RP (1998) The State-Trait Anxiety Inventory, Trait version: structure and content re-examined. Behav Res Ther 36:777-788. https://doi.org/10.1016/S0005- 
7967(98)00023-0

34. Wangel A-M, Molin J, Östman M, Jernström H (2011) Emergency cesarean sections can be predicted by markers for stress, worry and sleep disturbances in first-time mothers. Acta Obstet Gynecol Scand 90:no-no. https://doi.org/10.1111/j.1600-0412.2010.01056.x

35. Hung H-M, Ko S-H, Chen C-H (2014) The Association Between Prenatal Sleep Quality and Obstetric Outcome. J Nurs Res 22:147-154. https://doi.org/10.1097/jnr.0000000000000039

36. Sarberg M, Svanborg E, Wiréhn A-B, Josefsson A (2014) Snoring during pregnancy and its relation to sleepiness and pregnancy outcome - a prospective study. BMC Pregnancy Childbirth 14:15. https://doi.org/10.1186/1471-2393-14-15

37. Rouhe H, Salmela-Aro K, Gissler M et al (2011) Mental health problems common in women with fear of childbirth. BJOG 118:1104-1111. https://doi.org/10.1111/j.1471-0528.2011.02967.x

38. Lee H-J, Macbeth AH, Pagani JH et al (2009) Oxytocin: the great facilitator of life. Prog Neurobiol 88:127-151. https://doi.org/10.1016/j.pneurobio.2009.04.001

39. Pedersen CA, Chang SWC, Williams CL (2014) Evolutionary perspectives on the role of oxytocin in human social behavior, social cognition and psychopathology. Brain Res 1580:1-7. https://doi.org/10.1016/j.brainres.2014.07.033

40. Aral I, Köken G, Bozkurt M et al (2014) Evaluation of the effects of maternal anxiety on the duration of vaginal labour delivery. Clin Exp Obstet Gynecol 41:32-36

41. Kroll-Desrosiers AR, Nephew BC, Babb JA et al (2017) Association of peripartum synthetic oxytocin administration and depressive and anxiety disorders within the first postpartum year. Depress Anxiety 34:137-146. https://doi.org/10.1002/da.22599

42. Sund R (2012) Quality of the Finnish Hospital Discharge Register: A systematic review. Scand J Public Health. https://doi.org/10.1177/1403494812456637

43. Pietikäinen JT, Polo-Kantola P, Pölkki P et al (2019) Sleeping problems during pregnancy-a risk factor for postnatal depressiveness. Arch Womens Ment Health 22:327-337. https://doi.org/10.1007/s00737-018-0903-5

44. Mclntyre JPR, Ingham CM, Hutchinson BL et al (2016) A description of sleep behaviour in healthy late pregnancy, and the accuracy of self-reports. BMC Pregnancy Childbirth 16:. https://doi.org/10.1186/s12884-016-0905-0

\section{Figures}




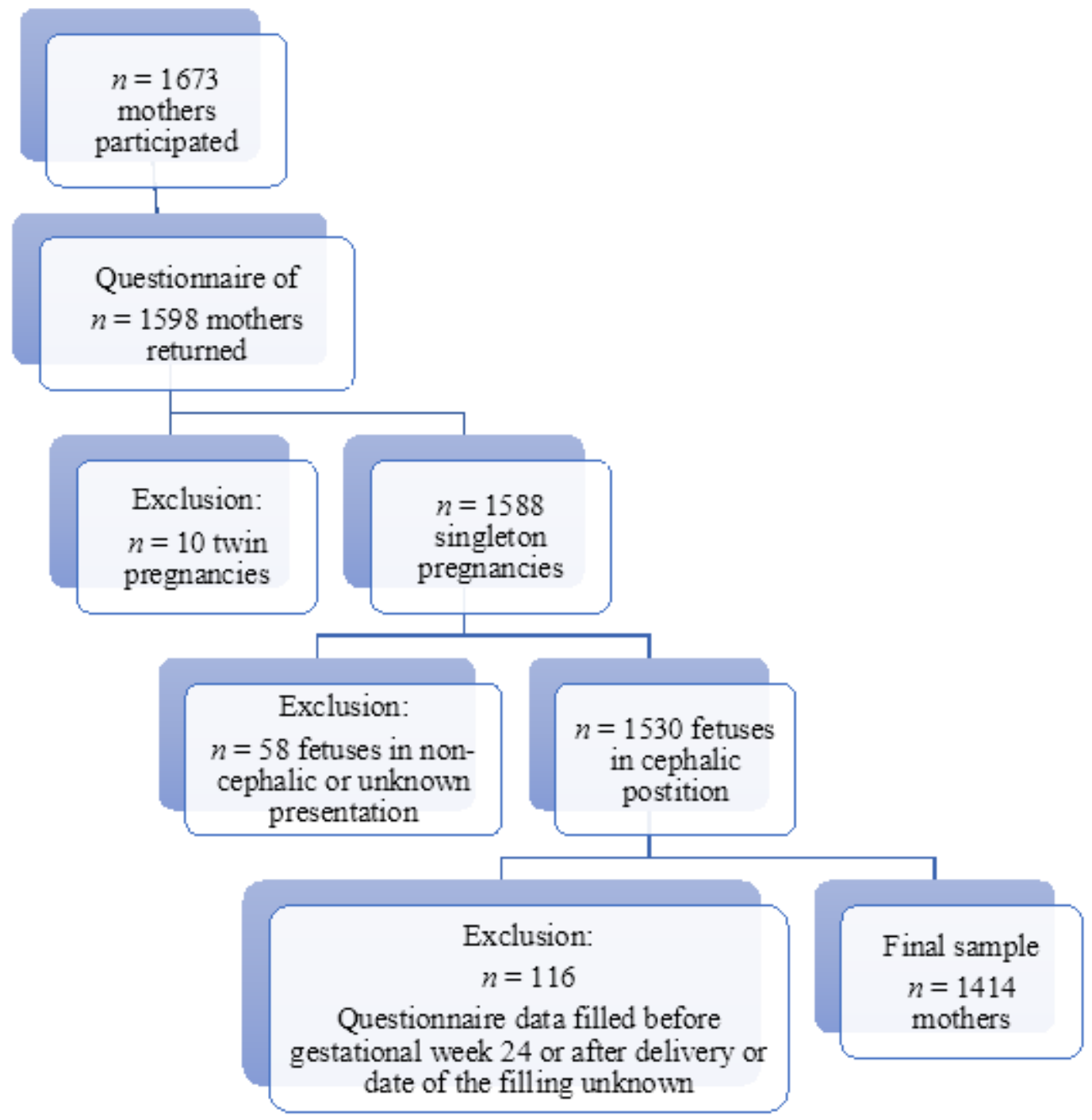

\section{Figure 1}

Mothers who had an incomplete questionnaire, missing delivery or newborn data or who had completed the questionnaire before gestational week 24 or after the delivery were excluded $(n=116)$. The mothers filled in the questionnaire on average in the gestational week 35 (range 24-41). Since the delivery outcomes were of especial interest in our study, we also excluded twin pregnancies $(n=10)$ and pregnancies with a fetus in other than a cephalic presentation $(n=58)$. A final sample of 1414 women remained to form the study population. The mothers were recruited between April 2011 and December 2012, and the infants were born between April 2011 - February 2013. During that time period, approximately 7700 infants fulfilling the inclusion criteria were born in the target area, but due to the exclusion criteria, maternal refusals, language difficulties, and a failure on the prenatal nurses' part to present the survey to the mothers, the sample coverage was approximately $20 \%$ (Figure 1 ). 